\title{
A ATUAÇÃO DO PSICÓLOGO NAS EQUIPES DE NÚCLEOS DE APOIO A SAÚDE DA FAMÍLIA
}

Cláudia dos Reis Pereira ${ }^{1}$

Aline Fernandes Alves ${ }^{2}$

\section{RESUMO}

INTRODUÇÃO: O Núcleo de Apoio a Saúde da Família (NASF) foi criado com a função de apoiar e expandir as ações desenvolvidas na Estratégia Saúde da Família (ESF), assim sendo, tem como função principal matriciar as equipes de referência (Leite, Andrade \& Bosi, 2013). A proposta do apoio matricial em saúde, visa oferecer de forma organizada, um suporte especializado aos profissionais e equipes responsáveis da atenção primária em saúde. Possibilitando a desfragmentação das ações executadas. Procura disponibilizar além do suporte assistencial, o técnico-pedagógico às equipes de referência. A psicologia enquanto ciência e profissão tem expandido sua atuação para diferentes ramos, que não apenas a clínica individual e privada. Neste contexto, é sabido que o campo da saúde pública tem se mostrado como promissor nicho de trabalho para os profissionais da psicologia. Todavia, ainda observamos dificuldades destes profissionais no que tange a construção de uma atuação para além da clínica psicológica tradicional. Entende-se que no contexto dos cuidados prestados na Atenção Primária em Saúde (APS), bem como em equipes do Núcleo de Apoio a Saúde da Família (NASF), tais dificuldades podem apresentar contornos específicos que distanciam as equipes do desenvolvimento adequado dos cuidados, tal qual é proposto pelas diretrizes do Ministério da Saúde. OBJETIVO: Conhecer e descrever a atuação de profissionais de psicologia em uma equipe do Núcleo de Apoio a Saúde da Família (NASF) de uma cidade do interior de Minas Gerais, estabelecendo comparações com o que a literatura e diretrizes do serviço propõe. MÉTODO: Realizou-se entrevistas semiestruturadas para coleta de dados com dois dos três psicólogos do NASF da cidade, devidamente autorizadas pelos entrevistados através de leitura e assinatura do termo de

\footnotetext{
${ }^{1}$ Acadêmica do curso de psicologia da Faculdade Patos de Minas - FPM. E-mail de contato: claudiapsicrp@gmail.com

${ }^{2}$ Docente do departamento de psicologia da Faculdade Patos de Minas - FPM.
} 

consentimento livre e esclarecido. O terceiro psicólogo não foi incluído na pesquisa pelo fato de ter se recusado a tal. Os dados produzidos foram registrados em áudio, e transcritas para análise posterior. O método utilizado foi qualitativo, buscando cartografar os processos de trabalho dos profissionais participantes, bem como aproximações e distanciamentos desta atuação com relação ao que as diretrizes preconizam. DISCUSSÃO E RESULTADOS: O estudo possibilitou não apenas a descrição de como se dá o trabalho do psicólogo nas equipes NASFs da cidade em questão, mas também a problematização de desafios e perspectivas comungada em outros municípios. A partir da leitura interpretativa dos dados construídos durante a pesquisa, foi possível evidenciar três eixos de análises nomeados da seguinte forma: (1) O profissional (co) responsável; (2) Psicólogo matriciador: ser ou não ser? e (3) (In) formados para a saúde pública. Através desses eixos foi possível compreender e discutir diversos entraves e potências do trabalho desenvolvido pelos profissionais participantes. Os resultados revelaram parcialidade nas execuções do trabalho preconizado pelo SUS, e dificuldades em exercer o papel na atenção básica. DISCUSSÃO E RESULTADOS: O estudo sugere mais pesquisas que levem a outras reflexões acerca do tema.

Palavras-chave: Atenção Primária em Saúde; NASF; Psicologia; Matriciamento. 